\title{
PENGARUH PROGRAM MANAJEMEN PERAWATAN TERHADAP PENURUNAN TINGKAT READMISI PADA PASIEN PENYAKIT PARU OBSTRUKTIF KRONIS
}

\author{
Ratna W. Rosyida ${ }^{*}$, Sa'bani N.A ${ }^{2}$, Ruly A. ${ }^{3}$, M.G.A Putra ${ }^{4}$, Anggi L. \\ Wicaksana $^{5}$
}
${ }^{1,2,3,4}$ Mahasiswa Magister Keperawatan, Fakultas Kedokteran, Kesehatan Masyarakat, dan Keperawatan Universitas Gadjah Mada, Yogyakarta
Email: ${ }^{1 *}$ ratna.w.r@mail.ugm.ac.id, ${ }^{2}$ sabani.nur.a@mail.ugm.ac.id,
${ }^{3}$ ruly_anita@yahoo.com, ${ }^{4}$ muhammadputraga1805@gmail.com.
${ }^{5}$ Program Studi Keperawatan Medikal Bedah, Fakultas Kedokteran, Kesehatan
Masyarakat, dan Keperawatan Universitas Gadjah Mada, Yogyakarta
Email: ${ }^{5}$ anggi.l.wicaksana@ugm.ac.id

\begin{abstract}
Abstrak
Penyakit paru obstruktif kronik (PPOK) memberikan dampak signifikan terhadap keberlangsungan hidup pasien. Strategi program perawatan perlu diaplikasikan untuk mencegah eksaserbasi akut sehingga dapat menurunkan readmisi pasien. Tujuan dari studi ini adalah untuk mencari bukti terkait pengaruh program perawatan terhadap readmisi pada pasien PPOK. Metode yang digunakan adalah pencarian literatur dengan mencari publikasi artikel 10 tahun terakhir dari database: Science Direct dan Pubmed dengan kata kunci: Chronic Obstructive Pulmonary Disease OR COPD AND care programme AND readmission. Peneliti memilih artikel original dan hasil review dengan kriteria inklusi: teks artikel utuh dan bahasa inggris. Kriteria eksklusi: tidak sesuai dengan rumusan masalah (PICOT), program rehabilitasi, dan seting unit gawat darurat. Peneliti melakukan review dengan mengecek duplikasi, judul, abstrak kemudian membaca artikel keseluruhan. Selanjutnya peneliti melakukan ekstrasi data dari artikel yang dipilih. Pencarian literatur mengikuti panduan PRISMA flowchart. Hasilnya menunjukkan bahwa terdapat 3 artikel yang memenuhi kriteria. Hasil temuan didapatkan bahwa program manajemen perawatan PPOK yang komprehensif dan terintegrasi memberikan manfaat dalam menurunkan tingkat readmisi pasien. Program manajemen perawatan yang dimaksud berupa perencanaan kepulangan pasien, kunjungan rumah atau follow-up serta perawatan pasca hospitalisasi. Program ini membutuhkan kerjasama multidisipliner dari perawat, fisioterapis, dokter dan apoteker. Simpulan dari studi ini adalah program manajemen perawatan yang komprehensif dan terintegrasi perlu dilakukan untuk menurunkan angka readmisi pasien PPOK.
\end{abstract}

Kata kunci : perawatan, PPOK, program, readmisi 


\begin{abstract}
Chronic obstructive pulmonary disease(COPD) provided a significant impact on life. It was important to develop strategy to prevent exacerbation. The study aimed to find outthe best evidence related to the effect of the care program on the readmission in COPD. The method used was the literature searched from the last 10 years publication from two databases: ScienceDirect and Pubmed. Keyword was Chronic Obstructive Pulmonary Disease OR COPD AND care programme AND readmission. Inclusion criteria were was full text articles in English, while the exclusion criteria were articles that not appropriate with review question,rehabilitation program, and articles with emergency setting. Four authors reviewed for duplicate articles, titles, and abstracts. Then, read the whole article. The literature search followed the PRISMA flowchart guidelines. The results indicated that there were 3 articles that meet the criteria. The findings showed that comprehensive and integrated COPD care management programs provided benefits in significantly reducing patient readmission. The management program consisted of patient's discharge planning, home visit or follow-up and rehabilitation care. The program required multidisciplinary collaboration including nurses, physiotherapists, doctors, and pharmacists. The conclusion isa comprehensive and integrated care management program is needed to be implemented to reduce the readmission rate.
\end{abstract}

Keywords : care, COPD, program, readmission

\section{PENDAHULUAN}

Penyakit paru obstruktif kronik (PPOK) merupakan penyakit yang timbul akibat dari adanya respon inflamasi kronis yang tinggi pada saluran nafas dan paru yang biasanya bersifat progresif dan persisten. Penyakit ini memiliki ciri berupa terbatasnya aliran udara yang masuk dan umumnya dapat di cegah dan di rawat (GOLD, 2015). PPOK adalah penyakit kronis saluran napas yang ditandai dengan hambatan aliran udara khususnya udara ekspirasi dan bersifat progresif lambat (semakin lama semakin memburuk), disebabkan oleh pajanan faktor risiko seperti merokok, polusi udara di dalam maupun di luar ruangan. Onset (awal terjadinya penyakit) biasanya pada usia pertengahan dan tidak hilang dengan pengobatan. Didefinisikan sebagai PPOK jika pernah mengalami sesak napas yang bertambah ketika beraktifitas dan/atau bertambah dengan meningkatnya usia disertai batuk berdahak atau pernah mengalami sesak napas disertai batuk berdahak dan nilai Indeks Brinkman $\geq 200$. Indeks Brinkman adalah jumlah batang rokok yang diisap, dihitung sebagai lama merokok (dalam tahun) dikalikan dengan jumlah rokok yang diisap per hari. Hasil yang didapat melalui kuesioner akan lebih rendah dibanding pemeriksaan spirometri karena PPOK baru ada keluhan bila fungsi paru sudah menurun banyak (Riskesdas, 2013).

Berdasarkan data World Health Organization (2017), prevalensi PPOK di dunia sebesar 251 juta kasus. Sementara prevalensi PPOK di Indonesia sebanyak 3,7 persen. Prevalensi PPOK tertinggi terdapat di Nusa Tenggara Timur $(10,0 \%)$. PPOK lebih tinggi pada laki-laki (242.256) dibanding perempuan 
(266.074). PPOK sebagian besar dialami oleh masyarakat berusia $>30$ tahun. PPOK memberikan dampak yang cukup signifikan terhadap keberlangsungan hidup pasien. Beberapa penelitian sebelumnya menunjukkan bahwa fungsi paru-paru dan kualitas hidup sangat dipengaruhi oleh frekuensi eksaserbasi PPOK dan frekuensi readmisi di rumah sakit. Selain itu pada pasien dengan PPOK memerlukan biaya perawatan yang tergolong cukup tinggi. Berdasarkan hal tersebut, sangat penting untuk dikembangkan berbagai macam strategi program perawatan (care programme) untuk mencegah eksaserbasi akut PPOK yang akan berdampak untuk menurunkan tingkat readmisi pasien (Aimonino dkk., 2008).

Care program merupakan suatu program dalam manajemen PPOK yang bermanfaat untuk menurunkan tingkat eksaserbasi yang akan berdampak pada penurunan tingkat readmisi. Care program dilakukan dengan melibatkan berbagai multidisiplin, baik dari perawat, fisioterapis, dokter, maupun social worker (Sridhardkk., 2008). Pertanyaan penelitian yang diajukan yaitu "bagaimana manfaat dari program manajemen perawatan pada pasien dengan PPOK.” Berdasarkan hal tersebut, artikel ini bertujuan untuk mencari bukti terkait pengaruh dari care program terhadap penurunan readmisi pada pasien dengan PPOK.

\section{METODE PENELITIAN}

Artikel ini merupakan integrative literature review dengan pencarian literatur mengikuti flowchart PRISMA (lihat gambar 1). Kriteria inklusi artikel: sesuai dengan tujuan penelitian, Full text,
Original research atau review article, menggunakan Bahasa Inggris. Artikel dieksklusikan jika membahas mengenai program rehabilitasi dan seting ruang gawat darurat. Database pencarian literatur menggunakan Science Direct dan Pubmed dengan kata kunci : Chronic Obstructive Pulmonary Disease OR COPD AND care programme AND Readmission. Peneliti membatasi artikel yang sesuai pada 10 tahun terakhir untuk memastikan bukti terkini. Uji eligibilitas menggunakan JBI critical appraisal tools dilakukan oleh 2 reviewer secara independen hingga didapatkan kesimpulan bahwa artikel layak dilakukan proses review.

\section{HASIL DAN PEMBAHASAN}

Dari hasil pencarian literatur didapatkan total 677 artikel dan hanya 3 artikel yang memenuhi kriteria. Artikel dieksklusikan karena tidak sesuai dengan tujuan pencarian, setting bukan di rawat inap atau komunitas, dan memberikan program rehabilitasi. Tiga artikel dengan masing-masing desain Randomized Controlled Trial (RCT), Cohort, dan Quasy Experiment. Hasil pencarian terdapat di flow chart PRISMA (gambar 1). Hasil uji eligibilitas menggunakan $J B I$ menunjukkan eligible dan digunakan sebagai literatur. Artikel yang didapat membahas mengenai program perawatan yang komprehensif melibatkan tim multidisiplin dan perawatan yang terintegrasi antara setting klinik dan setting komunitas. Hasil sintesis artikel terdapat di Tabel 1. 


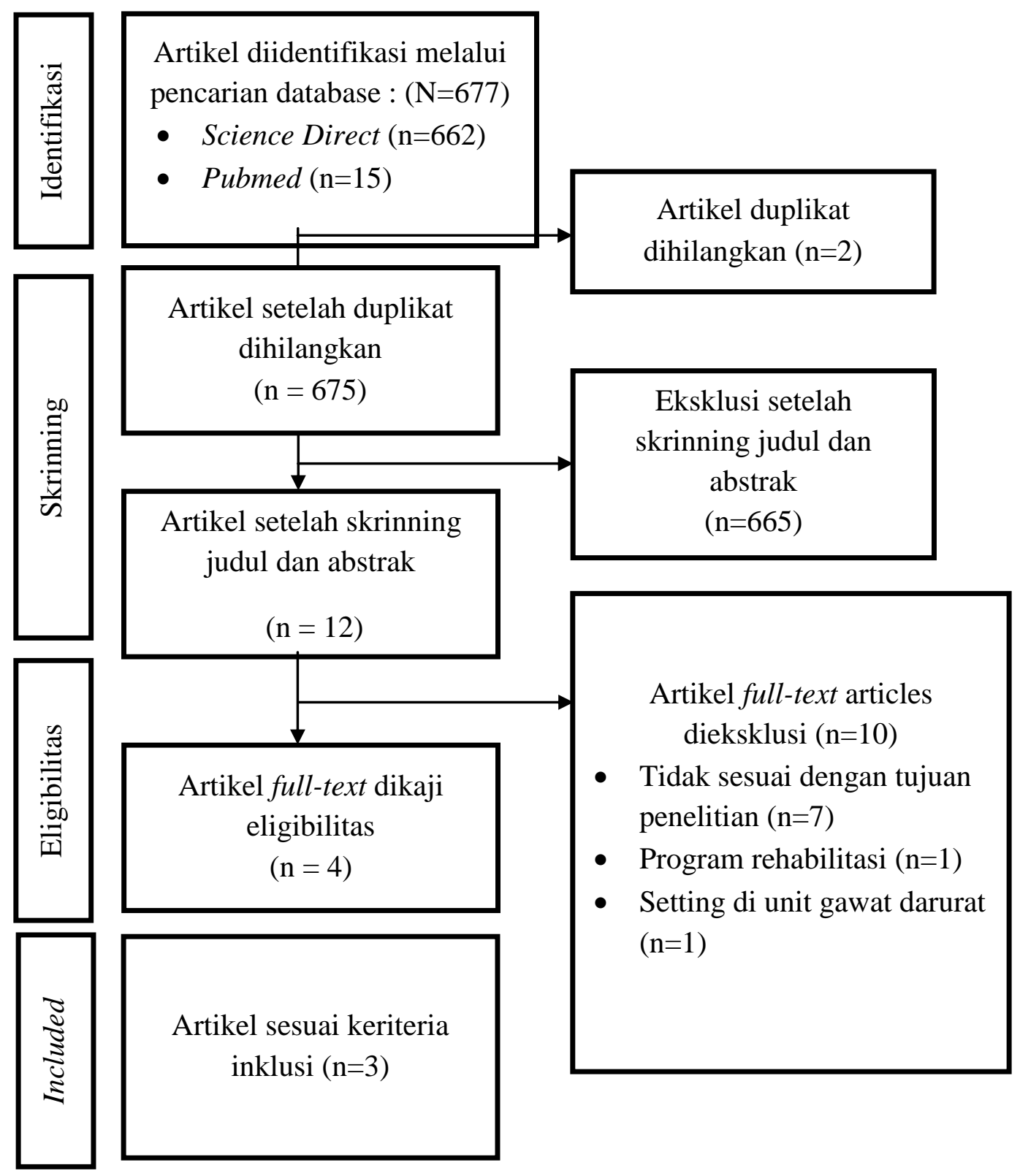

Gambar 1. Flow chart PRISMA 
Tabel 1. Hasil ekstraksi artikel

\begin{tabular}{|c|c|c|c|c|c|c|}
\hline Autor & Judul & Tujuan & $\begin{array}{c}\text { Populasi dan } \\
\text { Sampel }\end{array}$ & Intervensi & Hasil & Keterbatasan \\
\hline $\begin{array}{l}\text { Ko dkk. } \\
(2017)\end{array}$ & $\begin{array}{l}\text { Comprehensi } \\
\text { ve Care } \\
\text { Programme } \\
\text { for Patients } \\
\text { with Chronic } \\
\text { Obstructive } \\
\text { Pulmonary } \\
\text { Disease: A } \\
\text { Randomize } \\
\text { Control Trial }\end{array}$ & $\begin{array}{l}\text { Mengkaji } \\
\text { apakah } \\
\text { program } \\
\text { perawatan } \\
\text { komprehensi } \\
\text { f dapat } \\
\text { menurunkan } \\
\text { readmisi dan } \\
\text { lama hari } \\
\text { rawat PPOK }\end{array}$ & 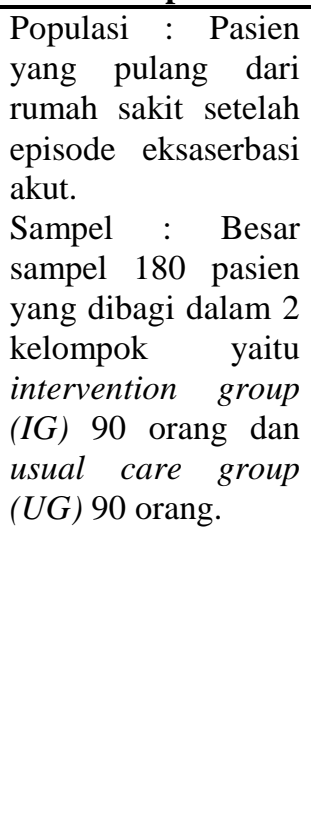 & $\begin{array}{l}\text { Kelompok } \begin{array}{c}I G: \\
\text { diwawancarai }\end{array} \text { Pleh } \begin{array}{r}\text { Pasien } \\
\text { perawat }\end{array} \\
\text { respirasi dan diberi edukasi } 2 \times 1 \\
\text { jam secara individu meliputi } \\
\text { pengetahuan seputar penyakit } \\
\text { PPOK dan perawatannya. Setiap } \\
\text { pasien juga mendapatkan latihan } \\
\text { dari fisioterapis tentang konservasi } \\
\text { energi, nafas dan pengeluaran } \\
\text { sputum. Mereka juga mendapatkan } \\
\text { pengobatan dari dokter respirasi } \\
\text { dan diberi nomor telepon yang } \\
\text { dapat dihubungi. Pasien menerima } \\
\text { telepon dari perawat respirasi dan } \\
\text { dievaluasi setiap } 3 \text { bulan dalam } 1 \\
\text { tahun. } \\
\text { Kelompok } U G: \text { Pasien diberikan } \\
\text { perawatan standar, yaitu } \\
\text { pengobatan oleh dokter respirasi } \\
\text { dan dievaluasi dalam } 12 \text { bulan. }\end{array}$ & $\begin{array}{l}\text { Setelah } 12 \text { bulan, kelompok IG } \\
\text { memiliki tingkat readmisi lebih } \\
\text { rendah dibanding UG (Incident } \\
\text { Rate }=1,24 \& 1,85) \text {. RR readmisi } \\
\text { sebesar } 0,668(95 \% \text { CI }=0,449- \\
\begin{array}{l}0,995 ; \quad \text { p }=0,047), \quad \text { sehingga } \\
\text { perbedaanya } \\
\text { signifikan. } \\
\text { Lama hari rawat lebih pendek } \\
\text { pada kelompok intervensi } \\
\text { daripada kelompok perawatan } \\
\text { biasa }(4,59 \pm 7,16 \& 8,86 \pm 10,24)\end{array}\end{array}$ & $\begin{array}{lr}\text { Pada penelitian ini } \\
\text { mengikutsertakan pasien } \\
\text { PPOK parah yang hanya } \\
\text { memiliki 1 } \\
\text { eksaserbasi } & \text { akut, } \\
\text { sehingga } & \text { ada } \\
\text { ketidakyakinan apakah } \\
\text { program komprehensif } \\
\text { akan efektif di } \\
\text { pelayanan kesehatan } \\
\text { yang lain atau tidak. } \\
\text { Sulit } \\
\text { komponen-komponen } \\
\text { mana yang menurunkan } \\
\text { readmisi. } \\
\text { Partisipan didominasi } \\
\text { pria (90\%). } \\
\text { Penelitian ini tidak } \\
\text { mengkaji keefektifan } \\
\text { biaya dari program yang } \\
\text { diuii. }\end{array}$ \\
\hline $\begin{array}{l}\text { Moullec } \\
\text { dkk. } \\
(\mathbf{2 0 1 2})\end{array}$ & $\begin{array}{l}\text { Effect of An } \\
\text { Integrated } \\
\text { Care Re- } \\
\text { Programme } \\
\text { on } \quad \text { Rospitalizatio } \\
\text { h of Patients } \\
\text { with Chronic } \\
\text { Obstructive } \\
\text { Pulmonary } \\
\text { Disease }\end{array}$ & $\begin{array}{l}\text { Mengkaji } \\
\text { pengaruh } \\
\text { dari program } \\
\text { perawatan } \\
\text { terintegrasi } \\
\text { pada } \\
\text { penurunan } \\
\text { kekambuhan } \\
\text { pasien } \\
\text { PPOK }\end{array}$ & $\begin{array}{l}\text { Population : Pasien } \\
\text { dengan disgnosis } \\
\text { primer PPOK dan } \\
\text { memiliki riwayat } \\
\text { rehospitalisasi } \\
\text { minimal } 48 \text { jam. } \\
\text { Sample : Pasien } \\
\text { dipilih } \quad \text { secara } \\
\text { random dari pasien- } \\
\text { pasien } r \text { yang } \\
\text { memenuhi } \quad \text { syarat }\end{array}$ & $\begin{array}{l}\text { Kelompok IC } \text { dirawat } \\
\text { menggunakan integrated care di } \\
\text { RS Sacre-Coeur yang terdiri dari } 2 \\
\text { komponen (1) Intervensi berpusat } \\
\text { pada pasien yang terdiri dari } 3 \times 1 \\
\text { jam sesi kelompok edukasi } \\
\text { manajemen diri, (2) organisasi } \\
\text { berbasis intervensi. manajemen } \\
\text { kasus. Edukasi manajemen diri } \\
\text { dilakukan oleh perawat spesialis } \\
\text { berpengalaman minimal } 15 \text { tahun }\end{array}$ & $\begin{array}{l}\text { Terdapat perbedaaan yang } \\
\text { signifikan pada penurunan } \\
\text { insiden rehospitalisasi pasien } \\
\text { PPOK selama } 12 \text { bulan antara IC } \\
\text { dan UC. Insiden hospitalisasi di } \\
\text { IC grup } 0,6 \text { kali dibanding UC } \\
\text { (OR } 0,44 ; 95 \% \text { CI } 0,23-0,85 \text { ). } \\
\text { Waktu rata-rata readmisi pada } \\
\text { UC } 217 \text { hari sedangkan IC } 281 \\
\text { hari. }\end{array}$ & $\begin{array}{lr}\text { Pengambilan } & \text { sampel } \\
\text { berdasarkan } & \text { pasien } \\
\text { masuk, bukan pasien } \\
\text { PPOK secara umum } \\
\text { sehingga } \\
\text { generalisasinya kurang. } \\
\text { Bias dalam pemilihan } \\
\text { mungkin terjadi karena } \\
\text { sampel diambil di RS } \\
\text { yang berbeda. Penelitian } \\
\text { ini tidak mengkaji }\end{array}$ \\
\hline
\end{tabular}




\begin{tabular}{|c|c|c|c|c|c|c|}
\hline $\begin{array}{l}\text { Ko dkk., } \\
\text { (2014) }\end{array}$ & $\begin{array}{l}\text { COPD care } \\
\text { programme } \\
\text { can reduce } \\
\text { readmissions } \\
\text { and in-patient } \\
\text { bed days }\end{array}$ & $\begin{array}{l}\text { Untuk } \\
\text { menginvesti } \\
\text { gasi efek } \\
\text { program } \\
\text { comprehensi } \\
\text { f COPD } \\
\text { management } \\
\text { dalam } \\
\text { menurunkan } \\
\text { readmisi } 1 \\
\text { tahun } \\
\text { sebelum dan } \\
\text { sesudah } \\
\text { program }\end{array}$ & $\begin{array}{l}\text { Pasien yang dirawat } \\
\text { di rumah } \text { sakit } \\
\text { karena eksaserbasi } \\
\text { akut COPD dengan } \\
\text { minimal } 2 \text { gejala } \\
\text { mayor atau } 1 \text { gejala } \\
\text { mayor dan } 1 \text { gejala } \\
\text { minor }\end{array}$ & $\begin{array}{l}\text { selama } 2 \text { hari persiapan pulang. } \\
\text { Sesi tersebut dilakukan melalui } \\
\text { modul program 'Living well with } \\
\text { COPD'. Pasien juga menerima } \\
\text { wawancara tentang gaya hidup } \\
\text { yang diadopsi dan diiminta } \\
\text { menulis rencana tindakan jika } \\
\text { terjadi kekambuhan. } \\
\text { Organisasi manajemen kasus, } \\
\text { perwat menginformasikan dokter, } \\
\text { apoteker dan ahli paru tentang } \\
\text { rencana tindakan. Kemudian } \\
\text { menyediakan nomor untuk } \\
\text { dihubungi oleh pasien. } \\
\text { Kelompok UC dirawat dengan } \\
\text { perawatan standar di RS St- } \\
\text { Eustache, yang terdiri dari } \\
\text { tindakan kunjungan dokter. } \\
\text { Tidak terdapat kelompok control. } \\
\text { Kelompok intervensi diperikan } \\
\text { program comprehemsive untuk } \\
\text { PPOK yang dilakukan selama } 16 \\
\text { minggu dengan intervensi: } \\
\text { a. Edukasi PPOK dan nurse } \\
\text { clinic oleh perawat respirasi } \\
\rightarrow \text { dilakukan di nurse clinic } \\
\text { selama } 2 \text { sesi (30- } 1 \text { jam) } \\
\text { dengan materi dasar PPOK } \\
\text { dan mengecek } \\
\text { membenarkan cara pasien } \\
\text { menggunakan inhaler } \\
\text { b. telephone hotline oleh perawat } \\
\text { respirasi pada minggu ke } \\
4,8,12,14 \text { untuk berdiskusi } \\
\text { dengan managemen COPD } \\
\text { dan memberikan saran2 }\end{array}$ & $\begin{array}{l}\text { Berdasarkan intervensi yang } \\
\text { diberikan, didapatkan hasil } \\
\text { jumlah admisi } 1 \text { tahun sebelum } \\
\text { program sebanyak } 2,15 \pm 1,91 \text {, } \\
\text { dan satu tahun setelah program } \\
\text { sebanyak } 1,54 \pm 2,11 \text { dengan } \\
\text { perbedaan rata-rata sebanyak } \\
0,61 \pm 1,97 \text { (penurunan } \\
\text { sebanyak } 28,4 \% \text { ). P-value } \\
<0,001 \text { Berdasarkan hasil } \\
\text { analisa statistic tersebut, dapat } \\
\text { disimpulkan bahwa jumlah } \\
\text { hospitalisasi menurun signifikan } \\
\text { sebelum dan sesudah diberikan } \\
\text { program comprehensive PPOK. }\end{array}$ & $\begin{array}{l}\text { Keterbatasan penelitian } \\
\text { ini tidak menggunakan } \\
\text { kelompok } \\
\text { sebagai pentrol } \\
\text { namun pembanding, } \\
\text { menggunakan desain } \\
\text { pre-post. Selain itu, } \\
\text { penelitian ini tidak } \\
\text { membandingkan } \\
\text { karakteristik dasar dari } \\
\text { subjek yang join dengan } \\
\text { program maupun yang } \\
\text { tidak mengikuti } \\
\text { program. Adanya } \\
\text { musim influenza dan } \\
\text { kondisi hunian pasien } \\
\text { juga tidak dijadikan } \\
\text { sebagai karakteristik }\end{array}$ \\
\hline
\end{tabular}


c. program rehabilitasi oleh

fisioterapis $(3 \mathrm{x} \quad 1$ minggu

selama 3 bulan, 1 jam tiap

sesi)

d. fast track doctor's clinic pada minggu 6 dan 16 post discharge diberikan terapi medis sesuai guideline dan manegemen komorbiditas

penyakit oleh dokter respirasi.

e. Doctor's visit : berat dan

tinggi diukur, dilakukan

spirometry pre-post

bronkodilator dan 6 menit tes

berjalan

Pengukuran : St George's

Respiratory

Questionnaire (SGRQ untuk QOL;

modified Medical Research

Council (mMRC) untuk perasaan

subjektif dispneu; data admisi

(jumlah admisi dan LOS) selama

12 bulan; 
Ko dkk. (2017), meneliti tentang program perencanaan yang komprehensif pada pasien PPOK untuk mengurangi readmisi dan lama hari rawat pasien PPOK. Penelitian berjenis randomized controlled trials (RCT) ini melibatkan kerjasama multidisipliner antara perawat respirasi, fisioterapis, dan dokter respirasi dalam memberikan intervensi. Perawat respirasi bertugas memberikan edukasi tentang sistem respirasi, patofisiologi PPOK, efek merokok, teknik mengonsumsi obat, manajemen sesak napas, nutrisi, manajemen diri, keterampilan mengurangi eksaserbasi, penenganan distress psikososial, support sistem dan pengetahuan tentang oksigenasi jangka panjang. Fisioterapis bertugas memberikan edukasi dan latihan fisik di rumah, serta memberi pengetahuan tentang pentingnya teknik pernapasan, mengeluarkan dahak dan konservasi energi. Dokter berperan menyesuaikan jenis-jenis obat dan memberikan manajemen PPOK sesuai dengan pedoman internasional. Pasien juga diberikan nomor telepon yang dapat dihubungi, sehingga mereka dapat bertanya tentang penyakitnya. Setelah 1 tahun pemberian intervensi, pasien dievaluasi dan didapatkan hasil bahwa rencana perawatan secara komprehensif dapat mengurangi readmisi dan lama hari rawat pasien dengan PPOK yang mengalami eksaserbasi akut.

Moullec dkk. (2012), meneliti pengaruh program perawatan terintegrasi untuk mengurangi rehospitalisasi pasien PPOK dengan rancangan studi kohort. Penelitian ini dilakukan selama 1 tahun. Intervensi atau paparan dalam penelitian ini adalah program edukasi manajemen diri dan manajemen kasus berbasis organisasi. Program tersebut telah dilakukan di rumah sakit Sacre-Coeur sebagai upaya mengurangi rehospitalisasi. Sebagai pembanding, peneliti menggunakan perawatan standar yang dilakukan di rumah sakit St-Eustache. Edukasi manajemen diri adalah program yang dilakukan oleh perawat spesialis yang memiliki pengalaman minimal 15 tahun. Edukasi yang dilakukan berkaitan dengan cara hidup yang baik untuk pasien PPOK. Sedangkan intervensi manajemen kasus diberikan oleh perawat case manager yang berperan mendukung program perawatan paska PPOK, menginformasikan kepada dokter, ahli paru-paru dan apoteker tentang rencana perawatan pasien, serta menyediakan call center untuk menambah informasi pasien tentang penyakitnya. Hasil dari penelitian ini, pasien yang menerima program perawatan terintegrasi yang terdiri dari edukasi manajemen diri dan manajemen kasus selama 1 tahun mengalami penurunan angka rehospitalisasi terutama pada pasien berjenis kelamin wanita.

Ko dkk. (2014), meneliti tentang program perawatan yang dilakukan untuk mengurangi readmisi pasien PPOK. Program perawatan yang dilakukan berupa perawatan yang komprehensif meliputi edukasi PPOK dan perawatan klinik oleh perawat respirasi, telephone hotline oleh perawat respirasi untuk berdiskusi dengan manajemen PPOK dan memberikan saran-saran, program rehabilitasi oleh fisioterapis, fast track doctor's clinic pada minggu 6 dan 16 post discharge diberikan terapi medis sesuai panduan dan manajemen komorbiditas penyakit oleh dokter respirasi serta kunjungan dokter. Melalui program tersebut, angka rehospitalisasi dan readmisi menurun antara sebelum dan sesudah diberikan program perawatan komprehensif.

Dari hasil studi literature dapat dinyatakan bahwa pemberian intervensi melalui care programme baik secara komprehensif maupun integrative memberikan dampak terhadap penurunan tingkat readmisi atau rehospitalisasi pada pasien. Namun, penelitian ini memiliki 
beberapa keterbatasan, yaitu artikel yang digunakan sebagai sumber literature sangat sedikit karena keterbatasan sumber dana kses database, artikel yang dibahas memiliki berbagai macam desain penelitian dan tidak semua artikel memiliki desain $R C T$, terdapat potensi bias terkait desain penelitian, sehingga peneliti merekomendasikan penelitian selanjutnya terkait care programme pada PPOK dengan desain penelitian RCT yang lebih terstruktur dan memperhatikan poinpoin penting dalam penelitian RCT.

\section{KESIMPULAN}

Hasil kajian dalam artikel ini membawa peneliti pada kesimpulan bahwa program managemen PPOK secara komprehensif dan terintegrasi dengan melibatkan berbagai multidisiplin yang menjalankan peran sesuai keahlian serta memberikan keperawatan yang berkelanjutan memberikan manfaat dalam menurunkan readmisi pada pasien.

\section{DAFTAR PUSTAKA}

Aimonino, R, N., Tibaldi, V., Leff, B., Scarafiotti, C., Marinello, R., Zanocchi, M., \& Molaschi, M. (2008). Substitutive "hospital at home" versus inpatient care for elderly patients with exacerbations of chronic obstructive pulmonary disease: A prospective randomized, controlled trial. Journal of the American Geriatrics Society, 56(3), 493-500. https://doi.org/10.1111/j.1532-5415.2007.01562.x.

GOLD. (2015). Global Strategy For The Diagnosis, Management, And Prevention Of Chronic Obstructive Pulmonary Disease. Global Initiative for Cronic Obstruktive Lung Disease. GOLD. USA.

Ko, F. W. S., Cheung, N. K., Rainer, T. H., Lum, C., Wong, I., \& Hui, D. S. C. (2017). Comprehensive care programme for patients with chronic obstructive pulmonary disease: a randomised controlled trial. Thorax, 72(2), 122-128. https://doi.org/10.1136/thoraxjnl-2016-208396.

Ko, F. W. S., Ngai, J. C. N., Ng, S. S. S., Chan, K. P., Cheung, R., Leung, M. Y., Pun, M. C., Hui, D. S. (2014). COPD care programme can reduce readmissions and in-patient bed days. Respiratory Medicine, 108(12), 1771-1778. https://doi.org/10.1016/j.rmed.2014.09.019.

Moullec, G., Lavoie, K. L., Rabhi, K., Julien, M., Favreau, H., \& Labrecque, M. (2012). Effect of an integrated care programme on re-hospitalization of patients with chronic obstructive pulmonary disease. Respirology, 17(4), 707-714. https://doi.org/10.1111/j.1440-1843.2012.02168.x.

Riskesdas. (2013). Riset Kesehatan Dasar (RISKESDAS) 2013. Laporan Nasional 2013, 1-384. https://doi.org/1 Desember 2013

Sridhar, M., Taylor, R., Dawson, S., Roberts, N. J., \& Partridge, M. R. (2008). A nurse led intermediate care package in patients who have been hospitalised with an acute exacerbation of chronic obstructive pulmonary disease. Thorax, 63(3), 194-200. https://doi.org/10.1136/thx.2007.077578.

World Health Association (WHO). (2017). Chronic obstructive pulmonary disease (COPD). Retrieved February 18, 2018, from http://www.who.int/entity/mediacentre/factsheets/fs315/en/ 
Jurnal Kesehatan. ISSN 1979-7621 (Print). ISSN 2620-7761 (Online). Vol. 11. No. 2. Desember 2018 